\title{
Percepções e avaliações do consumo de água em escolas públicas da mesorregião geográfica Triângulo Mineiro/Alto Paranaíba (MG)
}

\author{
Nágela Aparecida Melo', Marcio Ricardo Salla², Fernanda Ribeiro Garcia Oliveira ${ }^{3}$ \\ ' Doutora em Geografia, Professora, Universidade Federal de Uberlândia, Uberlândia, Brasil. \\ ${ }^{2}$ Doutor em Hidráulica e Saneamento, Professor, Universidade Federal de Uberlândia, Uberlândia, Brasil. \\ ${ }^{3}$ Mestre em Engenharia Civil, Professora na rede pública de ensino do estado de Minas Gerais, Brasil.
}

\section{Resumo}

Para a promoção da sustentabilidade ambiental faz-se urgente, em todos os segmentos da sociedade, a revisão de como o consumo de água é realizado e, sobretudo, a adoção de práticas e tecnologias que possibilitem melhor aproveitamento deste recurso e a diminuição do desperdício. Em unidades escolares públicas é frequente o uso inadequado da água e também perdas pelas condições de conservação dos sistemas hidrossanitários. Este artigo tem como cerne o questionamento sobre como o consumo de água é realizado em escolas públicas na mesorregião geográfica do Triângulo Mineiro. Os aspectos estudados foram separados por setor (banheiro, cozinha, área interna e externa), que incluíram a identificação do consumo de água, os procedimentos práticos na limpeza e manutenção e os hábitos dos usuários. A compreensão dos principais aspectos, relacionados a este assunto, é tomada como a referência principal para a proposição de diretrizes em projetos de educação ambiental voltados para o uso racional da água.

Palavras-chaves: Consumo de água em escolas; Educação ambiental; Uso racional de água.

\begin{abstract}
To promote environmental sustainability it is urgent, in all segments of society, the review of how water consumption is done and, especially, the adoption of practices and technologies to make better use of this resource and decreasing waste. In public school units is frequent the inappropriate use and also loss of water by conservation conditions of hydro-sanitary systems. The paper presented here is conducted to question about how water consumption is conducted in public schools in the region of Triangulo Mineiro. The aspects studied were separated by sector (bathroom, kitchen, indoor and outdoor area), which included the identification of water consumption, the practical procedures for cleaning and maintenance and the habits of users. Understanding the main aspects related is taken as main reference to proposition of guidelines in environmental education projects for the water rational use.
\end{abstract}

Keywords: Water consumption in schools; Environmental education; Water rational use. 


\section{INTRODUÇÃO}

O presente artigo tem como tema principal o consumo de água em escolas públicas. Como é amplamente conhecida, a água possibilita múltiplos usos e, no caso do ambiente escolar este recurso é empregado na elaboração de alimentos, na higiene pessoal, na limpeza dos espaços e nos equipamentos hidrossanitários.

O consumo de água envolve a quantidade de água propriamente usada para atender as necessidades dos usuários e também aquela que é desperdiçada ou perdida por diversos tipos de vazamentos e pela utilização de forma inadequada.

Para Cheung et al. (2009), "o termo desperdício compreende basicamente as perdas evitáveis, ou seja, correspondem claramente à negligência do usuário que não tem consciência ambiental. [...] Em geral, o desperdício está associado ao comportamento de uso".

Um aspecto que deve ser considerado é que o desperdício de água, por uso inadequado, está relacionado, em parte, com o desconhecimento e com a falta de informação da população em geral sobre as implicações disto no equilíbrio ambiental e no sistema de abastecimento e de esgotamento sanitário. Soma-se a isto a manutenção de hábitos ecologicamente incorretos na utilização da água nas atividades cotidianas. Conforme Vimieiro (2005), as reduções dos vazamentos e do uso inadequado de água tem que ser embasada em ações de caráter social, tecnológico e econômico.

Considerando esses aspectos anteriormente pontuados, a análise do consumo de água em residências e edifícios comerciais e de serviços abrange alguns aspectos principais: as demandas e necessidades de água conforme a população e atividades realizadas; como esse recurso natural é usado pelas pessoas, ou seja, se isto é feito ou não de modo que o desperdício seja o menor possível; a avaliação da ocorrência de perdas por vazamentos; a eficiência da estrutura e dos equipamentos hidráulicos do edifício.

O consumo de água também é influenciado pelo nível de esclarecimento e conhecimento dos usuários sobre a importância da conservação dos recursos naturais, da maior ou menor disponibilidade hídrica do local, da existência ou não de sistema de medição do volume consumido, dos preços pagos pela água, entre outros aspectos de natureza sociocultural.

No caso deste estudo, o consumo de água é analisado a partir dos hábitos e das práticas das pessoas que caracterizam como este recurso natural é usado no ambiente escolar. Portanto, o modo como atividades consumidoras de água são executadas nas escolas pode elevar ou diminuir a quantidade de água consumida. Isto foi verificado empiricamente em estudos tais como o de Gonçalves et al. (2005), Ywashima (2005) e nas experiências de implantação do Programa de Uso Racional da Água em escolas públicas do Estado de São Paulo.

A escola é aqui considerada como um espaço interessante para se discutir questões relacionadas com o consumo de água, pois se trata de um dos meios mais importantes de formação de cidadãos, os quais, entre outros conhecimentos, devem possuir a compreensão da importância dos recursos naturais para a sustentabilidade do Planeta.

$\mathrm{O}$ assunto abordado vincula-se diretamente à área da Educação Ambiental que tem como função "criar uma consciência e compreensão dos problemas ambientais e estimular a formação de comportamentos positivos", conforme o que ficou estabelecido na Conferência Intergovernamental sobre Educação Ambiental de 1977 (TOZONI-REIS, 2002).

Assim, para que os processos de criação e interpretação de informações, conceitos e significados necessários na educação ambiental aconteçam, faz-se necessário diagnosticar a realidade, ou seja, conhecer as interações e relações estabelecidas entre os sujeitos e o meio, bem como suas percepções e práticas ambientais.

Neste sentido, uma das relevâncias do presente estudo está no fato dele registrar e identificar os aspectos principais que caracterizam a formas do uso da água em escolas da rede pública estadual de Minas Gerais, localizadas em cidades da mesorregião geográfica Triângulo Mineiro/Alto Paranaíba.

Este tipo de conhecimento é fundamental para o desenvolvimento de metodologias e planos de educação ambiental que efetivamente venham contribuir na produção de novos padrões de comportamento em relação ao meio ambiente e aos recursos naturais.

Tendo em vista o que foi anteriormente ressaltado, apresentam-se, neste artigo, dados e análises de como o consumo de água é efetuado nas escolas selecionadas para o estudo e, em seguida, estabelece-se uma agenda de ações visando um melhor controle do consumo de água em ambientes escolares, 
baseada em medidas educativas que envolvam os membros da comunidade escolar de forma que cada grupo ou mesmo indivíduo tenha condições de se perceber como parte integrante do processo e com responsabilidades sobre o mesmo.

\section{METODOLOGIA}

\subsection{Seleção do objeto de estudo}

O objeto de estudo deste trabalho são doze escolas da rede pública estadual de ensino fundamental e médio localizadas em seis cidades pertencentes ao Polo Regional Triângulo Mineiro da Secretaria Estadual de Educação de Minas Gerais (SEE/MG). Estabeleceu-se como primeiro critério para a escolha das escolas, a seleção de estabelecimentos de ensino situados nas cidades que sediam Superintendências Regionais de Ensino (SRE) do Pólo Regional Triângulo da SEE/MG, com distância máxima de $250 \mathrm{~km}$ do município de Uberlândia, que é a sede deste Pólo Regional. Este critério limitou o recorte territorial nas cidades de Ituiutaba, Monte Carmelo, Patos de Minas, Patrocínio, Uberaba e Uberlândia, conforme identificação ilustrada na Figura 1.

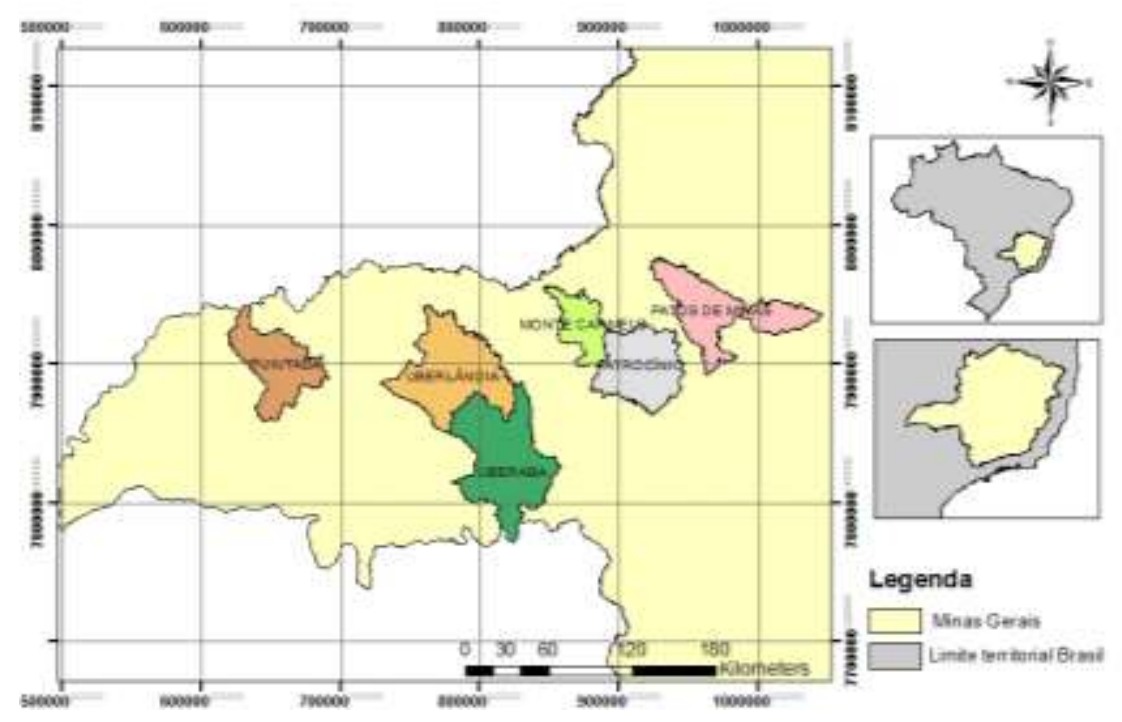

Figura 1: Identificação das cidades que englobam as escolas estudadas

O primeiro critério de escolha das escolas selecionou 167 estabelecimentos públicos de ensino. A partir daí, para redução deste número acentuado utilizou-se, como segundo critério de escolha, apenas as escolas que apresentaram a menor e maior média anual do valor do Indicador de Consumo mensal (volume consumido por dia e por agente consumidor), reduzindo para doze escolas (duas para cada cidade).

Os cálculos mensais do Indicador de Consumo foram efetuados para o período de fevereiro a dezembro de 2011, cujos dados de entrada fornecidos pela SEE/MG foram: número de alunos matriculados nas escolas estaduais; calendário escolar do ano de $2011 \mathrm{com}$ os respectivos números de dias letivos de cada mês; consumo mensal medido de água, mês a mês, relativo ao ano de 2011 (dados fornecidos pelo Departamento Municipal de Água e Esgoto dos municípios). Ressalta-se que os dados do mês de janeiro de 2011 foram excluídos por apresentar um consumo atípico devido ao período de férias escolares.

\subsection{Pesquisa de campo}

Os trabalhos de campo realizaram-se por meio de visitas técnicas nas escolas em estudo, em todos os turnos de funcionamento das atividades de ensino. Estas atividades viabilizaram a caracterização das atividades que envolvem o uso da água nas escolas e a obtenção de informações sobre os hábitos da comunidade escolar no uso da água. 
Para tanto, procedeu-se com:

a) o preenchimento de fichas padronizadas, a partir de entrevistas com diretores ou vice-diretores das escolas, para obter dados para a caracterização geral do uso da água nas instituições; b) aplicação de questionários aos usuários de água - professores (inclui o diretor e vice-diretor), supervisores ou orientadores, assistentes técnicos de educação básica (ATB) e os assistentes de serviços básicos (ASB), tendo em vista informações sobre como estes procedem durante a execução de atividades que consomem água.

Utilizaram-se seis tipos específicos de questionários, elaborados por Ywashima (2005) e adaptados para este estudo, os quais abrangem os pontos de consumo de água identificados na caracterização da escola e todos os usuários deste insumo (Tabela 1).

Tabela 1: Contexto dos questionários aplicados por setor da escola e indicadores do público alvo e do número total de respostas

\begin{tabular}{|c|c|c|c|}
\hline Tipo & $\begin{array}{l}\text { Setor da } \\
\text { escola }\end{array}$ & Indicadores & Conteúdo básico abordado \\
\hline B1 & Banheiros & $\begin{array}{l}\text { - Público alvo: todos os } \\
\text { segmentos } \\
\text { - No de funcionários: } 721 \\
\text { - Questionários respondidos: } 211 \\
\text { - Taxa de retorno: } 29 \%\end{array}$ & \multirow{4}{*}{$\begin{array}{l}\text { - Forma de uso dos banheiros } \\
\text { (torneiras dos lavatórios, dos } \\
\text { chuveiros, válvulas de descarga } \\
\text { das bacias sanitárias e dos } \\
\text { mictórios,) e bebedouros; } \\
\text { - Conhecimento técnico sobre } \\
\text { torneiras e bacias sanitárias que } \\
\text { economizam } \\
\text { Caracterização do processo de } \\
\text { limpeza; } \\
\text { - *Caracterização do processo de } \\
\text { limpeza. } \\
\text { - Caracterização do processo de } \\
\text { preparo dos alimento; } \\
\text { - Forma de uso das torneiras das } \\
\text { pias e tanque; } \\
\text { - Caracterização do processo de } \\
\text { limpeza. }\end{array}$} \\
\hline B2 & Banheiros & $\begin{array}{l}\text { - Público alvo: alunos } \\
\text { - No de alunos: } 10.152 \\
\text { - Questionários respondidos: } 510 \\
\text { - Taxa de retorno: } 5 \%\end{array}$ & \\
\hline B3 & Banheiros & $\begin{array}{l}\text { - Público alvo: ASB* responsável } \\
\text { - Questionários respondidos: } 35\end{array}$ & \\
\hline $\mathrm{C}$ & Cozinha & $\begin{array}{l}\text { - Público alvo: ASB responsável } \\
\text { - Questionários respondidos: } 25\end{array}$ & \\
\hline AI & $\begin{array}{l}\text { Área } \\
\text { interna }\end{array}$ & $\begin{array}{l}\text { - Público alvo: ASB responsável } \\
\text { - Questionários respondidos: } 29\end{array}$ & \multirow{2}{*}{$\begin{array}{l}\text { - Forma de uso das torneiras } \\
\text { utilizadas na limpeza geral; } \\
\text { - Caracterização do processo de } \\
\text { limpeza. }\end{array}$} \\
\hline AES & $\begin{array}{l}\text { Área } \\
\text { externa e } \\
\text { de serviço }\end{array}$ & $\begin{array}{l}\text { - Público alvo: ASB responsável } \\
\text { - Questionários respondidos: } 31\end{array}$ & \\
\hline
\end{tabular}

Por fim, os dados obtidos por meio dos questionários foram organizados sistematicamente e os seus principias resultados estão analisados no item seguinte.

\section{RESULTADOS E DISCUSSÕES}

\subsection{Identificação do consumo de água por setor}

A água é empregada nas atividades de limpeza e conservação dos vários ambientes (banheiros, cozinha, área administrativa, salas de aula, refeitório, corredores, pátios e quadras), no preparo de alimentos e refeição, nos equipamentos hidrossanitários e, eventualmente, na irrigação de jardins e hortas.

A caracterização e a avaliação dos usos da água foram estabelecidas a partir dos ambientes que compõem o espaço escolar, os quais são aqui denominados setores. Para tanto, foram identificados os 
seguintes setores: banheiros, cozinhas, setor interno e setor externo (Tabela 1).

No setor dos banheiros, que abrange os banheiros dos alunos, dos professores e demais servidores das escolas, a água é utilizada na limpeza do piso, louças sanitárias, paredes, janelas e no acionamento das peças hidrossanitárias (torneiras dos lavatórios e válvulas de descarga).

$\mathrm{Na}$ cozinha, setor escolar que se caracteriza pela execução de atividades próprias do preparo dos alimentos, a água é consumida na higienização das frutas, verduras, hortaliças, na cocção dos alimentos, na higienização das louças e demais utensílios e, na limpeza ${ }^{1}$ do piso, paredes e janelas.

Os banheiros e as cozinhas das escolas estudadas, em geral, apresentam piso cerâmico, paredes revestidas com azulejos e janelas compostas de perfil metálico e vidro.

O setor interno corresponde aos espaços dos prédios escolares nos quais estão localizadas as áreas administrativas (sala do diretor(a), vice-diretor(a) e secretarias), as salas de aula, a biblioteca, a sala dos especialistas e dos professores e o refeitório. Neste setor, a água é empregada na limpeza do piso, carteiras e janelas.

Os pisos dos diversos ambientes que compõem o setor interno são, em geral, de material cerâmico ou de cimento queimado e, as paredes apresentam-se rebocadas e com demãos de tintas. Em todas as escolas, as janelas são compostas de perfil metálico e vidro, com exceção de uma que tem suas janelas feitas de madeira e vidro. Nesta, mesmo no dia da faxina, não se joga água nas janelas, os vidros são limpos com pano úmido.

O setor externo é o conjunto de ambientes das escolas que não possui todos os fechamentos laterais, podendo ser coberto ou não. Compreendem os corredores, pátios, quadras, área de serviço, jardins e hortas. A água é utilizada de maneira mais frequente para lavar os corredores (praticamente todos os dias) e quando há presença de horta e/ou jardim, para regá-los.

A existência de horta foi observada apenas em duas unidades de ensino, sendo que, em uma delas, a horta era regada com a mangueira, e na outra, com a mangueira conectada a um aspersor mudado de lugar ao longo do dia. Na maioria das escolas é verificada a existência de jardins, ou pelo menos, espaços gramados com árvores ou arbustos, porém, estes espaços, em praticamente todas as escolas pesquisadas, não são irrigados.

As maneiras como as atividades consumidoras de água são executadas interferem no gasto deste recurso em qualquer espaço da sociedade. Isto, no caso específico deste estudo, inclui o modo como a água é empregada na limpeza e manutenção dos ambientes escolares e os hábitos dos usuários.

\subsection{Procedimentos práticos na limpeza e manutenção por setor}

Tomando isso como ponto de partida, avaliou-se, primeiramente, como ocorre o emprego da água durante a limpeza dos diferentes setores do ambiente escolar (Tabela 2).

Tabela 2: Formas de limpezas dos setores do ambiente escolar, segundo o modo de emprego da água, 2012

\begin{tabular}{|c|c|c|c|c|c|c|c|c|}
\hline \multirow{3}{*}{ Limpeza } & \multicolumn{8}{|c|}{ Modo de emprego da água, segundo atividades (\%) } \\
\hline & \multicolumn{2}{|c|}{ Banheiro } & \multicolumn{2}{|c|}{ Cozinha } & \multicolumn{2}{|c|}{ Área interna* } & \multicolumn{2}{|c|}{ Área externa** } \\
\hline & Balde & Mangueira & Balde & Mangueira & Balde & Mangueira & Balde & Mangueira \\
\hline Pisos & 92 & 8 & 92 & 8 & 100 & - & - & - \\
\hline $\begin{array}{l}\text { Louças } \\
\text { sanitárias }\end{array}$ & 92 & 8 & - & - & - & - & - & - \\
\hline $\begin{array}{l}\text { Paredes } \\
\text { janelas }\end{array}$ & 36 & 64 & 22 & 78 & - & - & - & - \\
\hline Corredores & - & - & - & - & 100 & - & 36 & 39 \\
\hline Pátios & - & - & - & - & - & - & 0 & 88 \\
\hline \multicolumn{9}{|c|}{$\begin{array}{l}\text { * Neste setor não foi computada a limpeza dos refeitórios que pode ocorrer ou não com o uso da mangueira; } \\
\text { ** Neste setor, a limpeza dos corredores e pátios é feita, também, sem o emprego de água, com o uso apenas de vassoura. } \\
\text { Por isso, os valores não totalizam } 100 \% \text {.; } \\
\text { Traço (-) indica que o dado não se aplica ao setor }\end{array}$} \\
\hline
\end{tabular}

${ }^{1}$ Limpeza: ação ou resultado de limpar(-se) (AULETE, 2004). A palavra limpeza será utilizada neste trabalho considerando as várias formas de realizá-la (varrendo, passando pano, lavando com a utilização de balde ou mangueira etc.) e também como sinônimo de higienização. 
Nos banheiros ${ }^{2}$ das escolas, os pisos e as louças sanitárias são lavadas todos os dias em cada um dos turnos, e uma vez por semana, dia considerado de faxina, lavam-se também as paredes e janelas. Constatou-se que durante a limpeza deste ambiente, a água é usada de forma a evitar o seu desperdício, visto que, em mais de $90 \%$ das escolas estudadas, a mesma é empregada como o auxílio de balde, procedimento que tende a gastar menos em relação ao lançamento feito com mangueira.

Nas cozinhas ${ }^{3}$, as paredes e janelas são lavadas no dia da faxina, cuja frequência varia de acordo com a escola, em algumas é semanal e em outras, quinzenal. Dados levantados apontam também que, neste setor, o emprego da água na limpeza se dá, principalmente, pelo uso de balde (Tabela 2). A mangueira é usada, geralmente, apenas nas faxinas.

No setor da área interna ${ }^{4}$ a água é usada praticamente apenas na limpeza do piso, sendo armazenada em baldes com o propósito de enxaguar o pano a ser passado no chão (Tabela 2).

No setor externo ${ }^{5}$ que abrange, entre outros, os corredores e os pátios, verificou-se que a limpeza ocorre com e sem o uso de água. Entretanto, das atividades realizadas neste setor, a limpeza dos pisos foi indicada como a que mais consome água. Na limpeza dos corredores emprega-se a água com maior frequência; na maioria das escolas foi citado que, em pelo menos um turno, joga-se água todos os dias e, nos demais realiza-se a varrição. Os pátios, no dia a dia, são apenas varridos. Eles são lavados apenas esporadicamente, nos dias de faxina que ocorrem uma vez por mês, ou por bimestre, ou por semestre, conforme a rotina de cada escola.

Constatou-se que a limpeza e manutenção dos ambientes escolares é feito com menor ou maior desperdício conforme os setores. O setor interno foi o ambiente escolar onde há indícios de um menor desperdício, seguido pelos banheiros e cozinha. Na área externa, mesmo com a realização de varrição dos pátios, pela extensão dos mesmos e pela forma como a mangueira é utilizada, o consumo desnecessário de água foi facilmente percebido.

\subsection{Hábitos dos usuários de água por setor}

Outros aspectos que interferem no consumo de água são os hábitos que as pessoas mantêm na utilização dos equipamentos hidrossanitários e no desenvolvimento das atividades consumidoras de água.

\subsection{Banheiros}

Observou-se que é mais frequente as torneiras permanecerem abertas somente durante o tempo necessário para enchimento do balde, ou no caso de uso da mangueira, para enxague das paredes (Tabela 3). Este tipo de procedimento corrobora para que a água seja usada de forma que ocorra menor desperdício.

Tabela 3: Hábitos dos entrevistados no manuseio dos equipamentos hidrossanitários nos banheiros

\begin{tabular}{lccl}
\hline Descrição & Hábitos & Respostas (\%) & Avaliação \\
\hline Torneira durante a limpeza & Aberta apenas na & 81 & Adequado \\
Torneiras dos lavatórios & atividade & 51 & Inadequado \\
Registro dos mictórios & Sempre aberta & 51 & Inadequado \\
Válvula de descarga & Aperta muito & 52 & Inadequado \\
\hline
\end{tabular}

Entretanto, um pouco mais de $50 \%$ dos usuários entrevistados indicaram que usam as torneiras dos lavatórios sempre abertas, os mictórios com o registro aberto direto e apertam muito o dispositivo

\footnotetext{
${ }^{2}$ Os dados referentes ao uso da água na limpeza dos banheiros foram obtidos a partir das respostas de questionários aplicados a 36 assistentes de serviços básicos (ASB), responsáveis pelo asseio e manutenção.

${ }^{3}$ A forma de utilização da água na cozinha foi obtida a partir dos dados analisados em 25 questionários respondidos pelas ASB (cantineiras e suas auxiliares).

${ }^{4}$ Os dados referentes ao uso da água no setor interno foram obtidos por meio de 36 questionários respondidos pelos ASBs responsáveis pela limpeza e manutenção do mesmo.

${ }^{5}$ Com relação ao uso da água no setor externo os dados foram obtidos por meio de 37 questionários respondidos pelos ASBs responsáveis pela limpeza e manutenção do mesmo.
} 
da descarga (Tabela 3). Com relação ao registro dos mictórios, foi possível constatar que nas escolas localizadas nas cidades de Ituiutaba, Monte Carmelo, Patrocínio e Uberaba, estes causam grande desperdício de água, uma vez que permanecem abertos durante todo o período de aula. Estes hábitos caracterizam, portanto, um consumo desnecessário de água, ou seja, desperdício de água de boa qualidade. Figueiredo (2007) dá uma ideia da amplitude do desperdício, o qual relata o consumo de aproximadamente 12 litros de água na escovação dos dentes mantendo a torneira aberta por 1 minuto, lembrando que o hábito correto de manter a torneira fechada durante o ato da escovação consumiria apenas 0,5 litros.

As atividades descritas na Tabela 3 devem ser executadas com economia deste insumo, a partir de alguns procedimentos como: ensaboar as mãos com a torneira fechada, abrir e fechar o registro do mictório após o uso e não apertar muito o dispositivo da descarga. Tais práticas podem gerar economias muito significativas no consumo de água, principalmente quando se considera o número total de usuários e de vezes que os equipamentos hidrossanitários são usados ao longo do dia ou do mês.

Ainda com relação aos banheiros, analisou-se a existência de chuveiros e o tempo que os mesmos permanecem ligados durante os banhos. Mesmo existindo chuveiros em pelo menos metade das escolas estudadas, estes praticamente não são usados. A utilização dos chuveiros foi registrada para apenas $4 \%$ dos entrevistados e isso só acontece nas escolas que têm turmas de período integral (Tabela 4). Os funcionários não fazem uso do mesmo pois, como trabalham meio período, responderam não haver necessidade de tomar banho na escola.

Tabela 4: Hábitos dos entrevistados no manuseio dos chuveiros

\begin{tabular}{|c|c|c|c|}
\hline Descrição & Hábitos & Respostas (\%) & Avaliação \\
\hline Utilização dos chuveiros & Sim & 4 & - \\
\hline \multirow{2}{*}{$\begin{array}{l}\text { Tempo que o registro do } \\
\text { chuveiro permanece aberto }\end{array}$} & Acima de 10 minutos & 60 & Inadequado \\
\hline & Mais de 15 minutos & 31 & Inadequado \\
\hline $\begin{array}{l}\text { Número de vezes que o } \\
\text { banheiro é utilizado por período } \\
\text { com uso de água }\end{array}$ & Duas ou mais vezes & 50 & - \\
\hline
\end{tabular}

Apesar dos chuveiros serem usados por uma parcela pequena de alunos, verificou-se que o tempo de banho da maioria excede 10 minutos (Tabela 4). Estes valores permitem estimar a ocorrência de um gasto desnecessário de água, lembrando que os chuveiros são responsáveis por um dos maiores consumos prediais de água. O uso de restritores de fluxo reduz para 3L.min-1 a vazão do chuveiro, mantendo a sensação de grande volume líquido (CHEUNG et al., 2009). Entretanto, o tempo de uso cabe somente ao usuário determiná-lo.

Considerando-se que a vazão média de um chuveiro elétrico seja de 4,5 L.min-1, aumentar o tempo de banho de 10 para 15 minutos constitui um gasto de $50 \%$ a mais de água, o que efetivamente caracteriza um desperdício demasiado, lembrando que um tempo de até 10 minutos é adotado como razoável para uma boa higiene corporal (CHEUNG et al., 2009).

Com relação ao número de vezes que os banheiros são utilizados, aferiu-se que metade dos entrevistados utilizam os banheiros com gasto de água, duas ou mais vezes por dia. Resumidamente, na limpeza dos banheiros não foi verificado gasto excessivo de água. Entretanto, quando analisou-se como este insumo é empregado pelos usuários deste setor, constatou-se a ocorrência de desperdício.

\subsubsection{Cozinhas}

Foram investigados os hábitos dos funcionários na execução das principais atividades que consomem água neste setor do ambiente escolar. Foram avaliadas as práticas de higienização das hortaliças, frutas e verduras, das louças e demais utensílios da cozinha e a forma como a carne é des- 
congelada (Tabela 5).

Constatou-se que, na maioria das cozinhas das escolas, a água é empregada de modo adequado, ou seja, com racionalidade, pois percebeu-se que prevalecem os hábitos que caracterizam um menor consumo. Porém, este aspecto não foi identificado na higienização das frutas e verduras, pois ao ser realizada com a torneira permanentemente aberta, causa um gasto elevado e desnecessário.

\subsubsection{Setor interno}

Os ASB responsáveis têm como hábito varrer ou não o ambiente a ser higienizado, o que depende do grau de sujidade do mesmo. Posterior a este procedimento, é passado um pano úmido com o auxílio de um rodo em todo o piso. A água armazenada no balde é utilizada para enxaguar o pano possibilitando assim, retirar o excesso de sujeira e havendo a necessidade, utilizá-lo mais uma vez para completar a limpeza do recinto.

Neste setor, a exceção no modo de limpeza foi encontrada nos refeitórios, que devido ao fato dos mesmos serem lavados praticamente todos os dias, consome mais água que outras práticas.

Tabela 5: Hábitos dos entrevistados na execução das atividades nas cozinhas

\begin{tabular}{|c|c|c|c|}
\hline Atividades & Hábitos & $\begin{array}{l}\text { Respostas } \\
(\%)\end{array}$ & Avaliação \\
\hline \multirow{2}{*}{$\begin{array}{l}\text { Higienização das } \\
\text { hortaliças }\end{array}$} & $\begin{array}{l}\text { Lava em água corrente / molho / } \\
\text { enxágua em um recipiente com água }\end{array}$ & 56 & Adequado \\
\hline & $\begin{array}{l}\text { Lava folha por folha em água } \\
\text { corrente }\end{array}$ & 44 & Inadequado \\
\hline \multirow[b]{2}{*}{$\begin{array}{l}\text { Higienização das } \\
\text { frutas } \\
\text { e verduras }\end{array}$} & Ensaboa e enxágua em água corrente & 84 & Inadequado \\
\hline & $\begin{array}{l}\text { Abre a torneira para molhar/ } \\
\text { ensaboa com a torneira fechada/ } \\
\text { enxágua em corrente }\end{array}$ & 16 & Adequado \\
\hline \multirow{2}{*}{$\begin{array}{l}\text { Higienização da } \\
\text { louça } \\
\text { e outros utensílios }\end{array}$} & $\begin{array}{l}\text { Coloca a louça em recipiente com } \\
\text { água e detergente / ensaboa / } \\
\text { enxágua em água corrente }\end{array}$ & 68 & Adequado \\
\hline & $\begin{array}{l}\text { Ensaboa e enxágua com a torneira } \\
\text { aberta }\end{array}$ & 32 & Inadequado \\
\hline \multirow{3}{*}{$\begin{array}{l}\text { Descongelamento } \\
\text { da carne }\end{array}$} & Na geladeira & 80 & Adequado \\
\hline & Em temperatura ambiente & 16 & Adequado \\
\hline & Em uma bacia com água & 4 & Inadequado \\
\hline
\end{tabular}

Na rotina de limpeza das salas de aulas, estas são diariamente varridas, sendo passado pano úmido apenas no quadro e no piso abaixo do mesmo, para retirar o excesso de pó de giz.

O modo de limpeza do setor interno, que foi verificado em praticamente todas as unidades de ensino, excluindo o refeitório e o dia de faxina nas salas de aula, permite avaliar que de todos os setores este é o que melhor utiliza a água na execução das suas atividades, pois a mesma é coletada nas torneiras de uso geral, abertas somente o tempo necessário para encher os baldes, em quantidade julgada suficiente para realizar o procedimento de higienização dos espaços.

\subsubsection{Setor externo}

Avaliou-se o modo como as torneiras são utilizadas durante a limpeza dos ambientes. A maioria das respostas apontou que as torneiras de uso geral permanecem abertas somente o tempo necessário para encher o balde (Tabela 6).

A forma de utilização das torneiras de uso geral é um ponto positivo no quesito economia de água, porém, faz-se necessário relembrar que, como citado anteriormente, quando se usa a mangueira (modo menos econômico de se empregar a água) para lavar os corredores e pátios, as torneiras, no geral, permanecem abertas durante todo o tempo em que são usadas. Portanto, observou-se que neste setor existe uma dualidade relacionada ao emprego da água. 
Tabela 6: Hábitos dos entrevistados na execução das atividades no setor externo

\begin{tabular}{llcccc}
\hline Descrição & \multicolumn{1}{c}{ Hábitos } & & Respostas (\%) & Avaliação \\
\hline $\begin{array}{l}\text { Torneiras durante a a } \\
\text { limpeza }\end{array}$ & $\begin{array}{l}\text { Abertas somente para } \\
\text { atividade } \\
\text { Permanentemente abertas }\end{array}$ & 94 & Adequado \\
\hline
\end{tabular}

\subsubsection{Comparação entre os hábitos dos usuários}

De uma maneira geral averiguou-se que, por meio das observações realizadas in loco, as práticas dos ASB responsáveis pela limpeza dos banheiros, das atividades pertinentes à cozinha e ao setor interno, têm se realizado de modo que o consumo de água não seja excessivo. No entanto, não se observou isto na limpeza do setor externo.

Verificou-se, em alguns casos, que o ASB responsável por algum ambiente do setor interno é também responsável pela execução de atividades no setor externo. No entanto, o seu comportamento com relação ao gasto de água diferencia-se dependendo do local. Assim, ao limpar ambientes do setor interno, usa-se a água de modo parcimonioso, como por exemplo, coletada em baldes. No entanto, no setor externo, o gasto excede o necessário, como por exemplo, com a utilização da mangueira geralmente conectada a uma torneira permanentemente aberta.

Tabela 7: Proposta deste estudo para funções e responsabilidades da comunidade escolar no projeto de redução de desperdícios no uso da água

\begin{tabular}{|c|c|}
\hline $\begin{array}{l}\text { Comunidade } \\
\text { escolar }\end{array}$ & Funções e responsabilidades no projeto de redução desperdícios \\
\hline Alunos & $\begin{array}{l}\text { - participar de programas de treinamento e esclarecimento sobre o uso racional } \\
\text { da água e conservação dos equipamentos hidrossanitários; } \\
\text { - atuar como multiplicadores de conhecimentos; } \\
\text { - construir novos hábitos de uso da água; } \\
\text { - fiscalizar e auxiliar na avaliação do projeto. }\end{array}$ \\
\hline Docentes & $\begin{array}{l}\text { - participar da elaboração e execução de programas de treinamento e } \\
\text { esclarecimento sobre o uso racional da água e conservação dos equipamentos } \\
\text { hidrossanitários; } \\
\text { - integrar a temática do projeto com os conteúdos de ensino das suas respectivas } \\
\text { disciplinas; } \\
\text { - prestar esclarecimentos para a comunidade escolar; } \\
\text { - auxiliar na fiscalização e avaliação do projeto. }\end{array}$ \\
\hline $\begin{array}{l}\text { Técnicos } \\
\text { Administrativos }\end{array}$ & $\begin{array}{l}\text { - participar de programas de treinamento e esclarecimento sobre o uso racional } \\
\text { da água e conservação dos equipamentos hidrossanitários; } \\
\text { - auxiliar no esclarecimento da comunidade escolar; } \\
\text { - fornecer dados e informações sobre a escola, o consumo de água, a } \\
\text { manutenção das instalações e equipamentos hidráulicos e custos relacionados } \\
\text { com estes assuntos; } \\
\text { - construir novos hábitos de uso da água; } \\
\text { - auxiliar na fiscalização e avaliação do projeto. }\end{array}$ \\
\hline ASB & $\begin{array}{l}\text { - participar de programas de treinamento e esclarecimento sobre o uso racional } \\
\text { da água e conservação dos equipamentos hidrossanitários; } \\
\text { - participar de treinamentos básicos para a identificação de problemas nos } \\
\text { sistemas hidrossanitários (especificamente para pessoal de limpeza e } \\
\text { manutenção); } \\
\text { - mudar práticas tradicionais nas suas atividades para aquelas com menor } \\
\text { consumo de água; } \\
\text { - atuar como multiplicadores de conhecimentos; } \\
\text { - auxiliar na fiscalização e avaliação do projeto. }\end{array}$ \\
\hline
\end{tabular}


Continuação tabela 7

\begin{tabular}{|c|c|}
\hline $\begin{array}{l}\text { Comunidade } \\
\text { escolar }\end{array}$ & Funções e responsabilidades no projeto de redução desperdícios \\
\hline $\begin{array}{l}\text { Coordenadores } \\
\text { e Diretores }\end{array}$ & $\begin{array}{l}\text { - elaborar e coordenar uma política de redução de desperdícios na escola; } \\
\text { - buscar apoio na estrutura administrativa do serviço público de educação; } \\
\text { - almejar e inscrever o projeto de redução desperdícios de água da escola em } \\
\text { editais externos de apoio; } \\
\text { - buscar apoio em universidades públicas, órgãos de pesquisa e ONG's. } \\
\text { - produzir e divulgar o relatório de acompanhamento e avaliação do projeto. } \\
\text { - estabelecer metas para o consumo de água; } \\
\text { - aplicar medidas de monitoramento de vazamentos; } \\
\text { - priorizar, na medida do possível, a substituição dos equipamentos } \\
\text { hidrossanitários (nas reformas e manutenções) por modelos de menor consumo } \\
\text { de água. }\end{array}$ \\
\hline
\end{tabular}

Os dados obtidos por meio dos diferentes questionários aplicados nas escolas selecionadas quantificaram e caracterizaram as atividades que envolvem o uso da água nos setores escolares e possibilitaram uma análise indutiva de que os usuários das escolas, no geral, têm um mínimo de informação e conhecimento sobre as atitudes que devem ser adotadas para a economia e conservação deste insumo. Entretanto, foi percebido que existem lacunas entre isto e as experiências práticas cotidianas de uso da água.

\section{CONSIDERAÇÕES FINAIS}

Este estudo permite estabelecer alguns pontos prioritários para o desenvolvimento de projetos voltados para a diminuição do consumo de água em escolas públicas, via redução de desperdícios nas atividades consumidoras. Vale ressaltar que, propostas completas para diminuição do consumo de água em escolas passam também por outras iniciativas como a detecção e o controle de vazamentos, o emprego de equipamentos hidrossanitários economizadores de água, a implantação de regimes de manutenções e, obviamente, pelo uso da água pautado em práticas racionais e ambientalmente adequadas.

Para isto, faz-se necessário o estabelecimento de uma política ambiental de uso racional da água e de uma práxis baseada em uma racionalidade ambiental, envolvendo todos os membros da comunidade escolar.

Um projeto piloto, para o desenvolvimento desses aspectos, pode ser iniciado justamente pelo controle do consumo de água nas atividades diárias da escola.

Em primeiro lugar, os usuários de água no ambiente escolar precisam ser identificados e receber informações e esclarecimentos de como influenciam no consumo e como podem contribuir no processo de diminuição deste. Portanto, os usuários em geral são: alunos (que apresentam a maior participação conjunto total de consumidores), servidores que executam a manutenção dos ambientes escolares, a limpeza e elaboração de refeições (estes atuam na execução de atividades e podem ser grandes consumidoras de água), os docentes, os técnicos administrativos, coordenadores e diretores.

Após esta etapa, deve-se proceder ao estabelecimento de funções e responsabilidade, envolvendo obviamente todos os grupos que integram a comunidade e considerando seus cargos e atribuições no contexto escolar, conforme ilustra a Tabela 7.

Este processo deve ser marcado por diagnósticos e avaliações frequentes, sempre tomando como referência a situação anterior ao projeto, a atual e a almejada. Estas informações devem ser amplamente divulgadas e trabalhadas nas salas de aulas, bem como nos demais espaços da escola. Para as avaliações pode se utilizar: a) indicador de consumo de água (L.pessoa-1.dia-1 ou L.pessoa-1.mês-1), indicador de ocorrência de danos propositais ou não nas instalações hidrossanitárias $\left(\mathrm{n}^{\circ}\right.$ registros. dia-1 ou $\mathrm{n}^{\circ}$ registros.mês-1); c) monitoramento da possível ocorrência de vazamento feito a partir de dados do hidrômetro; d) dados sobre os custos do consumo de água realizado mês a mês; e) índice de percepção dos usuários, conforme Ywashima (2005) e Oliveira (2013); entre outros.

Por fim, ressalta-se que um emprego mais eficiente da água pode ser conseguido em qualquer atividade que ela é utilizada, para tanto torna-se necessária a participação ativa dos usuários. A ideia 
de uso racional dos recursos hídricos deve fazer parte do comportamento dos consumidores, sendo essencial para o desenvolvimento sustentável.

\section{REFERÊNCIAS}

AULETE, C. Mini dicionário contemporâneo da língua portuguesa. Rio de Janeiro: Nova Fronteira, 896 p., 2004.

CHEUNG, P. B.; KIPERSTOK, A.; COHIM, E.; ALVES, W.C.; PHILIPPI, L.S.; ZANELLA, L.; ABE N.; GOMES, H.P.; SILVA, B.C.; PERTEL, M.; GONÇALVES, R.F. Consumo de água. In: GONÇALVES, R. F. (Coord.). Uso Racional de Água e Energia: conservação de água e energia em sistemas prediais de abastecimento de água. Vitória: ABES-PROSAB, 350 p., 2009.

FIGUEIREDO, C. R. Equipamentos hidráulicos e sanitários. Brasília: UnB, 2007. Disponível em: <http:// portal.mec.gov.br/seb/arquivos/pdf/profunc/13eqhidrasan.pdf>. Acesso em: 30 maio, 2014.

GONÇALVES, O. M.; ILHA, M.S.O.; AMORIM, S.V.; PEDROSO, L.P. Indicadores de uso racional da água para escolas de ensino fundamental e médio. Ambiente Construído, Porto Alegre, v. 5, n. 3, p.35-48, jul./set. 2005.

OLIVEIRA, F. R. G. Consumo de água e percepção dos usuários para o uso racional de água em escolas estaduais de Minas Gerais. 2013. 193 f. Dissertação (Mestrado em Engenharia Civil) - Universidade Federal de Uberlândia, Uberlândia, 2013.

TOZONI-REIS, M. F. C. Formação dos educadores ambientais e paradigmas em transição. Ciência \& Educação, Bauru, v. 8, n. 1, p. 83-96, jan., 2002.

VIMIEIRO, G. V. Educação ambiental e emprego de equipamentos economizadores na redução do consumo de água em residências de famílias de baixa renda e em uma escola de ensino fundamental. 2005. 105 f. Dissertação (Mestrado) - Escola de Engenharia, Universidade Federal de Minas Gerais, Belo Horizonte, 2005.

YWASHIMA, L. A. Avaliação do uso de água em edifícios escolares. 2005. 185 f. Dissertação (Mestrado) Curso de Faculdade de Engenharia Civil e Arquitetura, Universidade Estadual de Campinas, Campinas, 2005. 